\title{
Prevalence and reasons for missed dental appointments among patients treated by undergraduate dental students of Universiti Sains Islam Malaysia
}

Nur Farah Insyirah Khairuddeen ${ }^{1}$, Nur Haifa Najihah Ahmad Nazari1 ${ }^{1}$ Aws Hashim Ali Al-Kadhim², Ahmad Dzulfikar Samsudin ${ }^{3}$, Norashikin Amran ${ }^{3}$, Nor Faharina Abdul Hamid ${ }^{4}$, Azlan Jaafar5*

${ }^{1}$ Faculty of Dentistry Universiti Sains Islam Malaysia (USIM), Kuala Lumpur, Malaysia

${ }^{2}$ Department of Conservative Dentistry and Prosthodontics, Faculty of Dentistry Universiti Sains Islam Malaysia (USIM), Kuala Lumpur, Malaysia

${ }^{3}$ Department of Oral \& Maxillofacial Surgery, Pathology \& Medicine, Faculty of Dentistry Universiti Sains Islam Malaysia (USIM), Kuala Lumpur, Malaysia

${ }^{4}$ Centre for Restorative Dentistry Studies, Faculty of Dentistry, Sungai Buloh Campus, Universiti Teknologi MARA, Selangor, Malaysia

${ }^{5}$ Department of Periodontology and Community Oral Health, Faculty of Dentistry Universiti Sains Islam Malaysia (USIM), Kuala Lumpur, Malaysia

\begin{abstract}
Missed dental appointments drastically affect treatment proficiency and productivity of dental care facility. This study aimed to determine the prevalence and reasons for missed dental appointments among patients treated by clinical dental students of Universiti Sains Islam Malaysia (USIM). A total of 202 folders from year 2018 to 2020 treated by year 3 to year 5 dental students were retrieved from a pool of patient's record files using simple random sampling methods. Information on missed appointments was recorded. Other patients' information was kept confidential. The percentage of missed dental appointments among patients under clinical dental students' care was 37.1\% (95\% CI=30.7, 44.0). The majority of patients who missed dental appointments were male $(37.6 \%)$, adults (38.7\%) and employee $(40.2 \%)$ patients. The most reported reason for the missed dental appointment was due to personal matters (36\%) and the least was forgetfulness $(0.6 \%)$ and miscommunication (0.6\%). In conclusion, missed dental appointment commonly occurs among patients and frequently it was due to personal matters. A proper explanation by the students before scheduling an appointment is crucial to avoid any future missed dental appointments.
\end{abstract}

Keywords: dental care, dental students, missed appointments, noshow, reminder system

\section{Introduction}

Dental healthcare services in the academic dental centre are provided by the dentist,

dental specialist, and dental students under
Received:

17 August 2021

Revised:

22 September 2021

Accepted:

2 November 2021

Published Online:

4 March 2022

How to cite this article:

Khairuddeen, N. F. I., Ahmad

Nazari, N. H. N., Ali Al-Kadhim,

A. H., Samsudin, A. D., Amran,

N., Abdul Hamid, N. F., \& Jaafar,

A. . Prevalence and reasons for

missed dental appointments among patients treated by undergraduate dental students of Universiti Sains Islam Malaysia .IIUM Journal of Orofacial and Health Sciences, 3(1), 95-101.

https://doi.org/10.31436/ijoh s.v3i1.106

\section{Article DOI}

10.31436/ijohs.v3i1.106

*Corresponding author

\section{Address}

Faculty of Dentistry, USIM Level 15, Menara B, Persiaran MPAJ, Jalan Pandan Utama,

Pandan Indah, 55100

Kuala Lumpur, Malaysia

Telephone: +60342892520

Email address:

drazlan_jaafar@usim.edu.my close supervision. These services that are mostly utilised by patients are emergency treatment, preventive care or operative care (Jaafar et al., 2018). The cost for patients being treated by dental students is usually 
subsidised, whereas those being treated by dentists or specialists are charged at a normal rate. These subsidised treatments at the centre are the strategy to help fulfil the student's clinical requirements within their three years of clinical training (Serrano et al., 2017).

Patients often turn to academic dental centre for subsidise dental services without compromising the quality of care provided by the practitioners (Balhaddad et al., 2018). The quality of care includes dental capabilities and techniques, the manner during treatment, treatment procedures that could complete, the length of waiting time before treatment, and a complete and detailed explanation of the treatment plan (Lee et al., 2013). Lack of competency demonstrated by clinical dental students in managing some of the clinical aspects and longer treatment time can affect patient satisfaction that leads to the frequent missed dental appointments made (Lee et al., 2013; Machado et al., 2015; Bukhari et al., 2016).

In Malaysia, students are required to complete a structured clinical training before they are allowed to sit for a professional examination. These consist of minimum clinical experience (MCE) and expected clinical experience (ECE). The regulations were set to ensure that students are equipped with adequate skills in practising independent and safe dentistry. In a study, lack of exposure to certain clinical procedures was found to be associated with inadequate training and reduce confidence level (Ali et al., 2017).

Missed dental appointments may cause loss of practical hours in clinical training and opportunity for students to provide oral care to other patients under their obligation. If a cancellation was made in less than 24 hours from the appointment time, it would be difficult for the student to contact another patient as a last-minute replacement. This will cause the affected student to require an extension to their clinical sessions to complete their clinical requirements (Awartani, 2003). The students claimed that many of the missed scheduled appointments by their patients had caused a loss of valuable clinical sessions. Although a number of personal reminders had been sent, this problem is still recurring. However, there is limited evidence available for the faculty to determine and address the issues. Missed dental appointments can also adversely affect patients. Frequently missed dental appointments can cause incomplete dental treatment which can reduce the quality of care received by patients and delay the treatment needed (McQueenie et al., 2019). Postponement in oral care provision can shift a mild form of disease to a severe form such as in case of carious lesions, gingival and periodontal diseases which eventually results in tooth loss.

The prevalence of missed dental appointments varied across studies between 9\% to 40\% (Awartani, 2003; Holtzman et al., 2013; Albaloushi and Da'ar, 2015; Storrs et al., 2016; Tandon et al., 2016). The most common excuse for missed dental appointments among patients was forgetfulness, busy with other matters and not brought by a parent for regular dental care (Tandon et al., 2016; Onyejaka et al., 2018; Kirby and Harris, 2019; Penzias et al., 2019). Factors that contributed to the missed dental appointments include age, gender and occupation status (Storrs et al., 2016; West et al., 2020). Thus, this study aims to determine the prevalence, reason, and treatment status of missed dental appointments among patients in the academic centre under clinical dental student's care. In addition, factors associated between sociodemographic profile and missed appointments were also assessed.

\section{Materials and Methods}

This was a cross-sectional study conducted at Dental Polyclinic, Faculty of Dentistry, Universiti Sains Islam Malaysia (USIM). The study was approved by the Research Ethics Committee of USIM [Ref no: USIM/JKEP/2020-111]. Patients' folders were retrieved from a pool of patient's records by a simple random sampling method. The patient's folders were taken from year 2018 to 2020 treated by year 3 to year 5 dental students. Patients who 
received dental treatment from outpatient clinics or specialist clinics were excluded.

In this study, we defined missed dental appointments as "a patient who does not turn up or absent without advanced notice or reschedule or cancel the appointment through call or any other methods within 24 hours". The information of missed dental appointments was indicated from the patient's records written by clinical dental students in the folder at least once. Additional information of missed dental appointments was also recorded including the frequency, reasons and status of the dental treatment. The status of treatment was recorded as ongoing, referred for specialist treatment, terminated or case completed.

The demographic information of patients in the folder i.e., age of first registration, sex and occupational status were documented. Age was further categorised as children (below 18 years old), adults (18 to 59 years old) and elderly (60 years and above). All the patients' information documented for the study purposes were kept anonymous and confidential.

\section{Data analysis}

Descriptive statistics (percentage and frequency) were assessed for different variables. Statistically significant difference was evaluated using the Pearson's Chisquare test at $95 \%$ confidence $(p<0.05)$. Data were analysed using IBM SPSS Program for Windows (version 26.0 SPSS Inc., Chicago, IL USA).

\section{Results}

A total of 202 patients' records were successfully retrieved. The mean age of the patient was 46.4 years old $(\mathrm{SD}=17.81)$ ranging from 4 to 77 years old. The percentage of patients who missed dental appointments was $37.1 \%$ (95\% CI=30.7, 44.0) with more than half of them missed dental appointments once (Figure 1).

The majority of missed dental appointment patients were among the adult age group $(39.9 \%)$, male (37.6\%) and employee $(48.2 \%)$ patients as tabulated in Table 1. No significant association was found between the patient's demographic profiles and missed dental appointments.

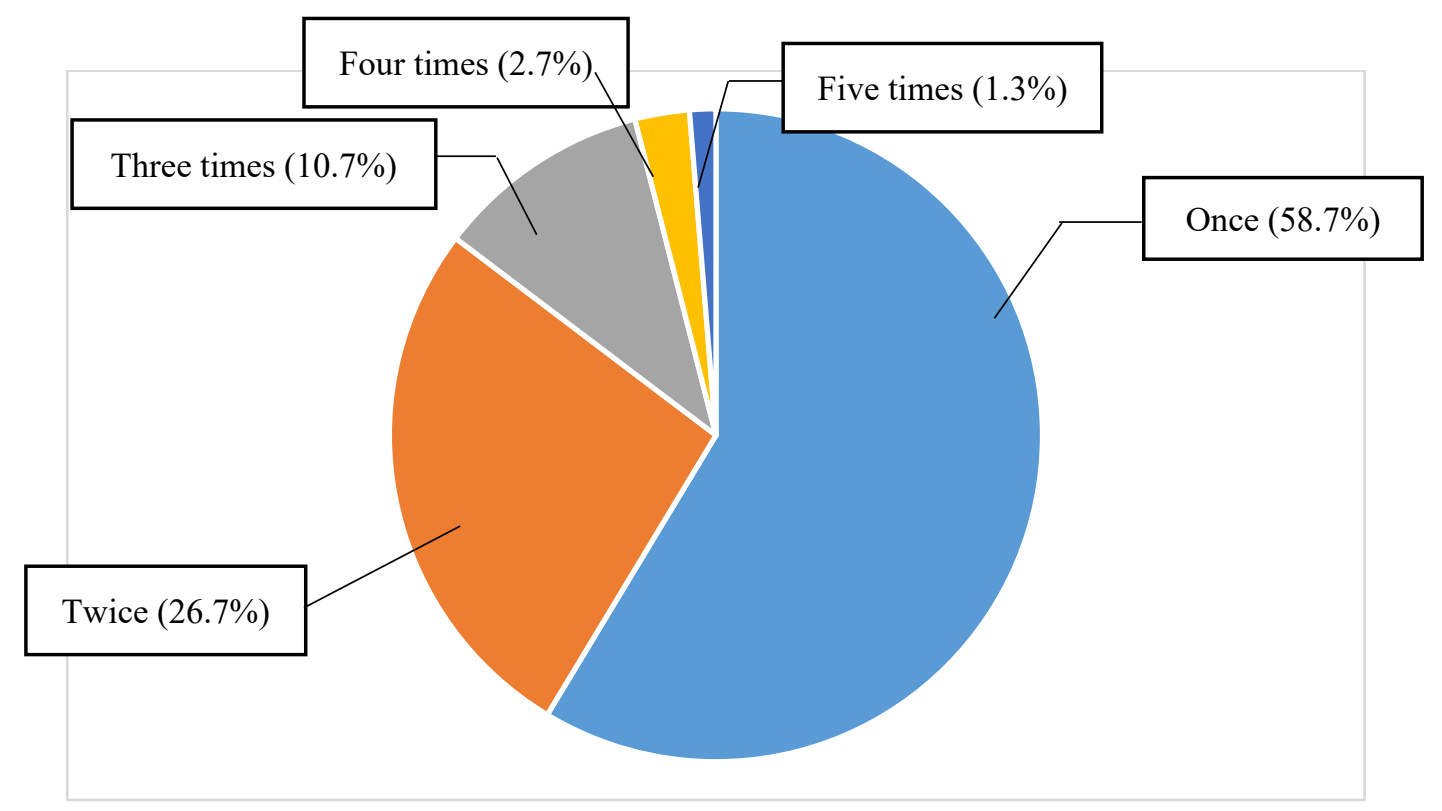

Figure 1. Frequency of missed dental appointments among patients 
Table 1. Missed dental appointment according to the characteristic of patients

$\begin{array}{lccc}\text { Characteristic } & \begin{array}{c}\text { Came for appointment } \\ \mathbf{n}(\%)\end{array} & \begin{array}{c}\text { Missed dental appointment } \\ \mathbf{n}(\%)\end{array} & \text { p-value } \\ \text { Age } & 8(72.7) & 3(27.3) & 0.478 \\ \quad \text { Children } & 83(60.1) & 55(39.9) & \\ \text { Adult } & 36(67.9) & 17(32.1) & \\ \quad \text { Elderly } & & & 0.884 \\ \text { Gender } & 63(62.4) & 38(37.6) & \\ \quad \text { Male } & 64(63.4) & 37(36.6) & 0.428 \\ \text { Female } & & & \\ \text { Occupation } & & & \\ \quad \text { Unemployed } & 75(65.2) & 35(34.8) & \\ \text { Employee } & 52(59.8) & \end{array}$

Figure 2 shows the reason for patients' missed dental appointments in USIM dental students' polyclinic. A quarter of patients reported reasons for missed dental appointments because of personal matters whereas forgetfulness $(0.6 \%)$ and miscommunication $(0.6 \%)$ were the least common reasons.

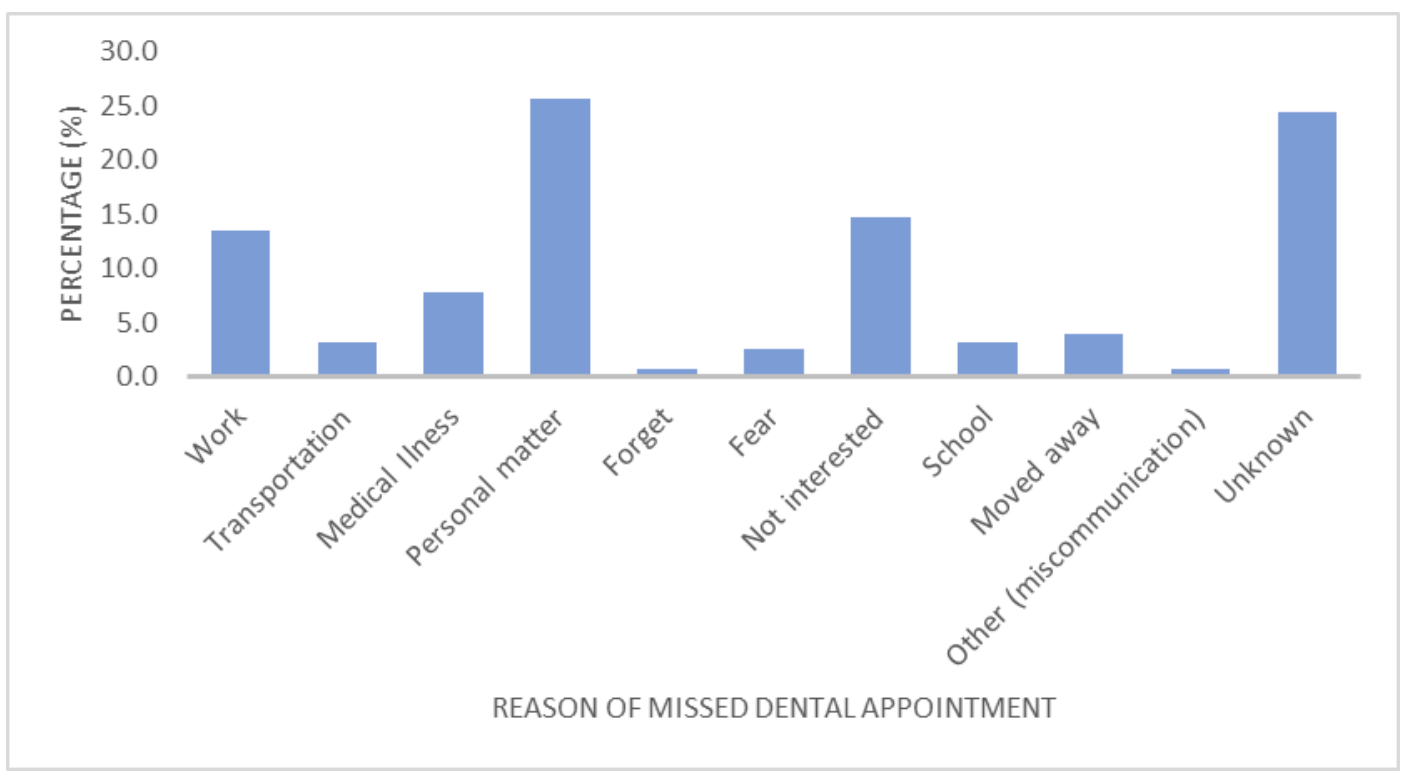

Figure 2. The reason for missed dental appointments among patients 


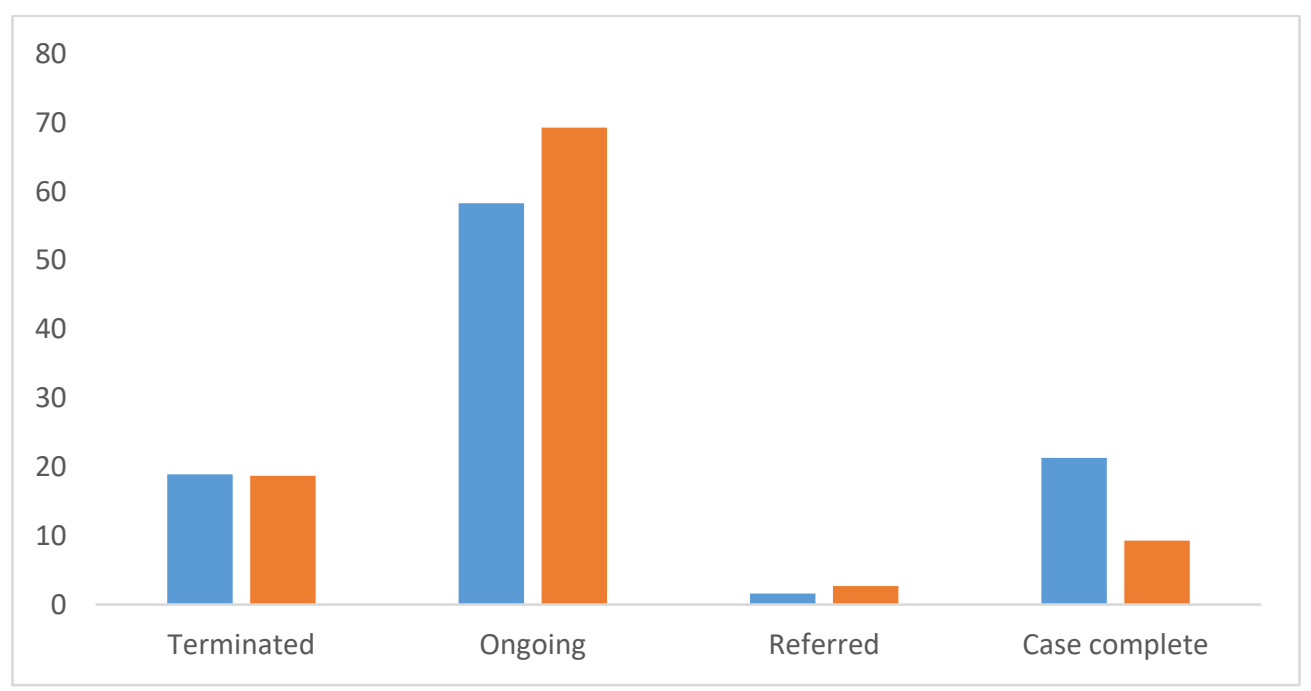

Figure 3. Treatment status of patients attended to academic dental centre between missed and non-missed appointment (Blue=did not missed appointment; Orange=missed appointment)

\section{Discussion}

A patient that attended our dental centre will undergo pre-assessment screening by a registered dentist in an outpatient clinic before being assigned to an undergraduate dental clinic or consultant assessment clinic. The waiting list will be stratified based on the complexity of the case. Suitable patients will be put on waiting list before being called by clinical students for further comprehensive dental examination in the respected clinic. After clinical examination and treatment plan agreed by patients, students are responsible to manage patients' appointments until case completion. Most of the time, patients' appointments will be scheduled through a text message or personal call. Students are encouraged to send a gentle reminder to ensure no lastminute cancellation. These reminders are for record purposes to avoid unreasonable termination. This method is proven to significantly improve the appointment rate and reduce the number of missed appointments (Penzias et al., 2019). With proper appointment policies, reminders and patient's motivation, a missed appointment can be effectively controlled. Furthermore, it allows the affected student to arrange for a replacement for the clinical session. However, no data has been collected to establish this veracity.
This study showed that almost forty per cent of the patients treated by clinical dental students in this dental academic centre missed their dental appointment. The percentage of missed appointments in this study is slightly higher compared to other similar studies in another academic dental centre (Awartani, 2003; Storrs et al., 2016). Less number of samples collected in this study could be the reason. Further research with a large number of samples is highly recommended.

Previous studies have shown that transportation, forgetfulness and miscommunication were the most common reasons for missed appointments among patients (Albarakati, 2009; Onyejaka et al., 2018; AlSadhan, 2013). Surprisingly, the findings of this study showed the opposite results where these reasons were the least quoted reasons for missed appointments. This is most likely due to the dental care policy being practice in USIM which encourages that patients need to be reminded through call or text messages at least 24 hours before their scheduled appointment. Frequent communication through text messages and phone call help to reduce patient-dentist miscommunication problems (Storrs et al., 2016). As USIM dental centre is located in the middle of the 
city, the most frequent issue of transportation presented in previous studies is not an area of concern in this study as patients can easily reach the clinic by different modes of transportations. On the other hand, this study found that onequarter of patients missed their dental appointments due to personal reasons however, no clear evidence has been shown and the exact cause needs further investigation. Moreover, a high percentage of unknown reasons for missed appointments should be evaluated carefully. This could be due to improper documentation of missed appointments by the dental student during their clinical sessions. Thus, it is important to emphasize on taking good clinical notes to avoid data records errors.

This study showed that a higher number of patients who missed their appointments were still undergoing treatment. According to a guideline provided by the dental centre, non-attending patients with more than three times will be put under consideration for termination. Therefore, it is important to discuss and inform patients regarding the cancellation policy to avoid more missed appointments in the future without any valid reason. This is to ensure the valuable clinical sessions are not wasted. It has been suggested that no-show rates are higher among patients who missed appointments in the previous three appointments (Tsai et al., 2019). However, there were still some patients who missed more than three appointments being treated by USIM dental students. Major clinical procedures such as endodontic therapy or crown/bridge work that have been treated halfway could be the reason for patients' retainment. According to Storrs et al. (2016), after relief from acute symptoms of an initial endodontic session, the patient was less inclined to resume the treatment as they believed the treatment has completed. Thus, the treatment plan should be discussed to obtain full cooperation from patients. In the meantime, a supportive environment demonstrated by the oral healthcare personnel can help the patient to understand the importance of appointmentkeeping behaviour to ensure frequent dental clinic visits as planned (Horsley et al., 2007; Sbaraini et al., 2012).

The limitations in this study were data extraction was done using conventional method which involved retrieving patient's records using patient folder. Currently, the record keeping system were shifted gradually to electronic records; thus, there is a possibility of some data were excluded in this study. In addition, our study only focusses on the reason of missed appointment from the dental student's perspective only. Thus, for future research, it is suggested to include more variables to further understand the reason why missed appointment among patient occur.

\section{Conclusion}

More than one-third of dental students' patients missed their dental appointments. A quarter of the patients who missed these appointments is due to personal matters. Patients who adhere to their scheduled dental appointment mostly complete their treatment under dental students. A proper explanation of the clinic policies and dental procedures to be taken by the students before scheduling an appointment is essential to avoid any missed dental appointments so that patients' treatment plans can be completed. The findings of this study could provide useful preliminary data for the university to further improved the record-keeping system among dental student and structure remainder system to reduce missed appointment rate.

\section{Acknowledgement}

The authors are most grateful to the Faculty of Dentistry, USIM for the approval and support to conduct this study at the Dental Polyclinic.

\section{Conflict of Interest}

The authors declare that they have no financial or other conflicts of interest in relation to this research and its publication. 


\section{References}

Albaloushi H. M. \& Da'ar O. (2015). Do patients with varying demographic and regional characteristics equally miss appointments across dental specialties? European Scientific Journal,11(12), 4560.

AlBarakati S. F. (2009). Appointments Failure Among Female Patients at a Dental School Clinic in Saudi Arabia. Journal of Dental Education, 73(9), 11181124.

Ali K., Slade A., Kay E., Zahra D. \& Tredwin C. (2017). Preparedness of undergraduate dental students in the United Kingdom: a national study. British Dental Journal, 222(6), 472-477.

AlSadhan S. A. (2013). Frequency of missed and cancelled appointments in King Saud University orthodontic clinic. King Saud University Journal of Dental Sciences, 4, 77-80.

Awartani F. (2003). Broken Appointment Behavior in a Dental School Environment. Journal of Contemporary Dental Practice, 4(4), 100-107.

Balhaddad A. A., Alshammari A., Alqadi A. \& Nazir M. A. (2018). Patient Satisfaction with Dental Services and Associated Factors in a Saudi Dental Institution. Journal of Clinical and Diagnostic Research, 12(12), ZC36-ZC39.

Bukhari O. M., Sohrabi K. \& Tavares M. (2016). Factors affecting patients' adherence to orthodontic appointments. American Journal of Orthodontics and Dentofacial Orthopedics, 149, 319-24.

Holtzman J. S., Atchison K. A., Gironda M. W., Radbod R. \& Gornbein J. (2014). The association between oral health literacy and failed appointments in adults attending a university-based general dental clinic. Community Dentistry and Oral Epidemiology, 42, 263-270.

Horsley B. P., Lindauer S. J., Shroff B., Tüfekçi E., Abubaker A. O., Fowler C. E., et al. (2007). Appointment keeping behavior of Medicaid vs nonMedicaid orthodontic patients. American Journal of Orthodontics and Dentofacial Orthopedics, 132, 4953.

Jaafar A., Nasir W. M., Ab Mumin N., Elias N. N. A. \& Mohd Sabri M. A. (2018). Reasons for seeking dental care among adults at an academic dental centre and the associated factors. Archives of Orofacial Sciences, 13(2), 104-111.

Kirby J. \& Harris J. C. (2019). Development and evaluation of a 'was not brought' pathway: a team approach to managing children's missed dental appointments. British Dental Journal, 227(4), 291297.

Lee K. T., Chen C. M., Huang S.T., Wu Y. M., Lee H. E., Hsu K. J., et. al. (2013) Patient satisfaction with the quality of dental treatment provided by interns. Journal of Dental Sciences, 8, 177-183.

Machado A. T., Werneck M. A. F., Lucas S. D. \& Abreu M. H. N. G. (2015). Who did not appear? First dental visit absences in secondary care in a major Brazilian city: a cross-sectional study. Ciência \& Saúde Coletiva, 20(1), 289-298.

Mark J. Storrs M.J., Helen M. Ramov H. M. \& Ratilal Lalloo R. (2016). An Investigation into Patient NonAttendance and Use of a Short-Message Reminder
System at a University Dental Clinic. Journal of Dental Education, 80(1), 30-39.

McQueenie R., Ellis D. A., McConnachie A., Wilson P. \& Williamson A. E. (2019) Morbidity, mortality and missed appointments in healthcare: a national retrospective data linkage study. BMC Medicine, $17(2)$.

Onyejaka N. K., Emele I. E. \& Eboh O. F. (2018). Appointment Failure among Dental Patients Attending a Government Dental Centre in Enugu, Nigeria. Pesquisa Brasileira em Odontopediatria e Clinica Integrada, 18(1), e4004.

Penzias R., Sanabia V., Shreeve K. M., Bhaumik U., Lenz C., Woods E. R., et al. (2019). Personal Phone Calls Lead to Decreased Rates of Missed Appointments in an Adolescent/Young Adult Practice. Pediatric Quality and Safety, 4(4), e192.

Sbaraini A., Carter S. M., Evans R. W. \& Blinkhorn A. (2012). Experiences of dental care: what do patients value? BMC Health Services Research, 12(177).

Serrano C. M., Botelho M. G., Wesselink P. R. \& Vervoorn J. M. (2018). Challenges in the transition to clinical training in dentistry: An ADEE special interest group initial report. European Journal of Dental Education, 2018, 1-7.

Tandon S., Duhan R., Sharma M. \& Vasudeva S. (2016). Between the Cup and the Lip: Missed Dental Appointments. Journal of Clinical and Diagnostic Research, 10(5), ZC122-ZC124.

Tsai W. C., Lee W. C., Chiang S. C., Chen Y. C. \& Chen T. J. Factors of missed appointments at an academic medical center in Taiwan. Journal of the Chinese Medical Association, 82(5), 436-442.

West A., Stones T. \& Wanyonyi K. (2020). Deprivation, demography and missed scheduled appointments at an NHS primary dental care and training service. British Dental Journal, 228(2), 98-102. 